\title{
A Survey of Internal Combustion Engine Condition Monitoring and Fault Detection Techniques
}

\author{
Sabry Allam ${ }^{1}$, Mohammed Abdo ${ }^{2}$ and Mohamed khairy ${ }^{3}$ \\ Professor $^{1}$, Assistance Professor ${ }^{2}$, Ph.D. Scholar ${ }^{3}$ \\ Automotive Technology Department, \\ Faculty of Technology and Education, \\ Helwan University, \\ Cairo, Egypt.
}

\begin{abstract}
The internal combustion engine is the heart of cars, trucks, and many machines. It is the main source of movement and operation, and it consists of different mechanical sectors. Due to usage and aging, different faults can appear which affect engine operation and managing. Any small engine fault can turn into a major malfunction if it is not monitored and maintained at the proper time. Therefore, monitoring the performance of motors can save time and costs, improve their performance, and help them operate safely. Fault diagnosis, fault detection, and condition monitoring terms are used to describe similar concepts detection of any abnormality or deviation from the engines or machines normal condition. This paper describes a summary of the existing condition monitoring and fault detection techniques of the internal combustion engine, which are used for information collection to ensure operational safety, performance, reasonable maintenance, pollution prevention, and cost reduction.
\end{abstract}

Keywords: Internal Combustion Engine; Fault Detection; Instantaneous Speed; Performance Parameter; Oil Analysis; Vibration Signal.

\section{INTRODUCTION}

Internal Combustion Engine (ICE) has been the basic part of the car business since its initiation. Indeed, even as the efficient power vitality activity moves to the forward, the internal combustion engine continues to dominate both conventional and hybrid vehicles. ICE are contains a lot mechanical systems, every system has different mechanical flaws, the early stages fault detecting can help to avoid larger and more serious faults. Any small mechanical error can turn into a major malfunction if it is not monitoring and maintained with proper maintenance over time. Fault detection increase efficiency and safety, improve performance, and reduce overall system lifetime costs [1]. Therefore, monitoring these parts performance can save a lot of money, time, and maintain the acceptable of the engine performance. Trucks and some private vehicles are used diesel engine vastly due to its dynamic performance and good economy. The performance of the diesel engine has been developed due to the growing concern about environmental and noise pollution [2]. Engine performance is affected through power output, fuel consumption, exhaust emissions, and combustion efficiency when a failure occurs [3]. The failure increases the diesel engine operating cost [4]. Diesel engines operate at high pressure and temperature especially during a compression and combustion strokes that causes spontaneous ignition of the fuel. In addition, the speed of engine rotation varies from a few hundred to 3000 or more revolutions per minute. The high pressure, high temperature, and high speed increase the risk of faults occurring within the engine, Figure 1 shows faults classified according to engine systems and components [5]. 


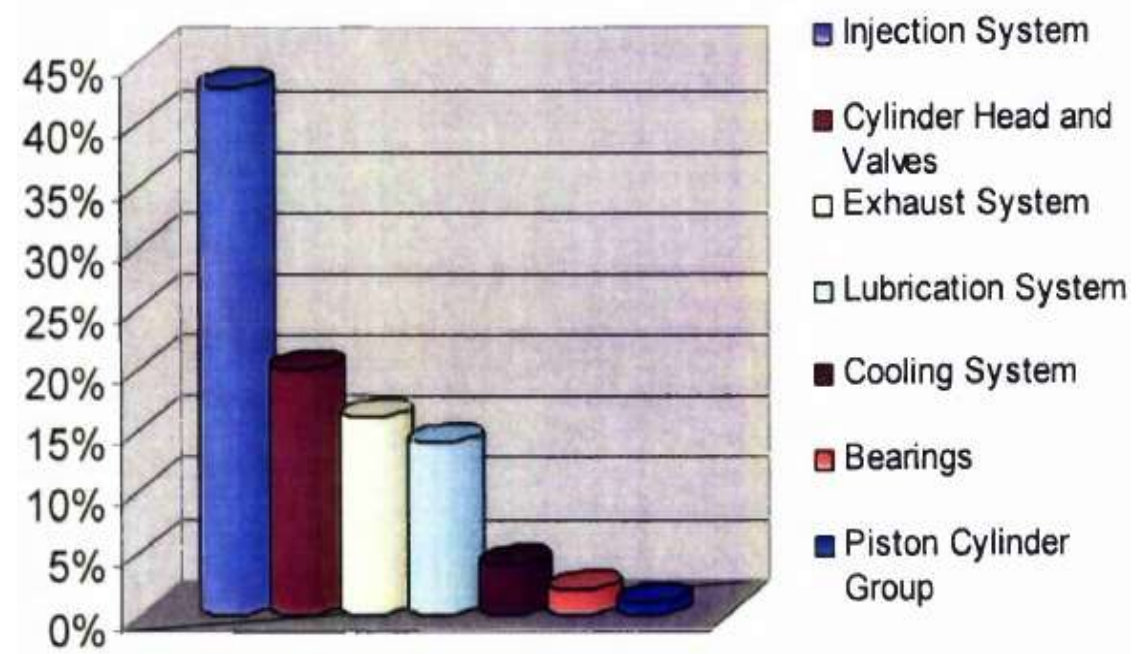

Figure 1: Principal faults in diesel engine [5].

\section{MAINTENANCE STRATEGIES}

While it is true that all machines are degrading systems, meaning that wear eventually will lead to a need for maintenance or replacement. Proper maintenance and care can improve machinery health and longevity. To reduce the downtime, and thus increase the availability of machines, several maintenance programs have been developed. The maintenance program that is implemented for a given machine usually depends on the importance of that machine [6].

J. S. Rao [7], A. R. Mohanty [8] and R. B. Randall [9] are classified the maintenance programs into three categories (Reactive maintenance, Preventive maintenance, and Predictive maintenance). Reactive maintenance is a strategy in which machines work to break or fail to do their job. At this point, maintenance is required either in the form of replacement parts or a complete replacement. This maintenance program is usually performed only for unimportant machines and equipment and is usually associated with large repair costs and long downtime. Preventive maintenance is a strategy that is planned and implemented according to the manufacturers' instructions or based on prior knowledge of the failure. Repairs are made periodically, and the parts that have had an average life expectancy are exceeded they are replaced with new ones. The positive aspect of this maintenance strategy is that downtime is reduced, since maintenance is planned, and machines are less susceptible to serious failures. However, a downside is that some of the parts that are being replaced probably have some remaining useful life. Predictive maintenance is a condition-based strategy. Device health indicators are monitored and deviation from normal values may indicate a problem. From Information about the current state of the device is expected in the future, Maintenance can be planned and executed accordingly. Hence, the work stops minimized and made available to the maximum.

\section{CONDITION MONITORING OF MACHINES}

Status monitoring is divided into two categories a permanent monitoring and intermittent monitoring. The permanent monitoring is related to the state monitoring systems where the transformers are permanently connected to the monitored machine. These systems are usually implemented for important machines, and monitoring is done continuously, so sudden changes can be detected and the machine can be turned off if necessary. Intermittent monitoring is monitoring where there is a predetermined interval for data acquisition, and therefore it is directed more towards long-term trends rather than sudden changes that may occur. Intermittent monitoring can be used on most devices by setting the data acquisition interval to an appropriate value. Moreover, intermittent monitoring can be carried out with power transformers and permanently installed transformers that are moved between the measuring points [9].

R. B. Randall [9] divided machine condition monitoring into three phases, fault detection, fault diagnosis, and fault prognosis. Prognosis is the phase where the future condition of the machine is predicted, the remaining useful life of the machine (components). A. K. Jardine et al [10] divided the condition-based maintenance program into three steps: (1) data acquisition, (2) data processing, and (3) decision making. Building on this, the process of condition-based maintenance can be summarized with the flow chart presented in Figure 2. 


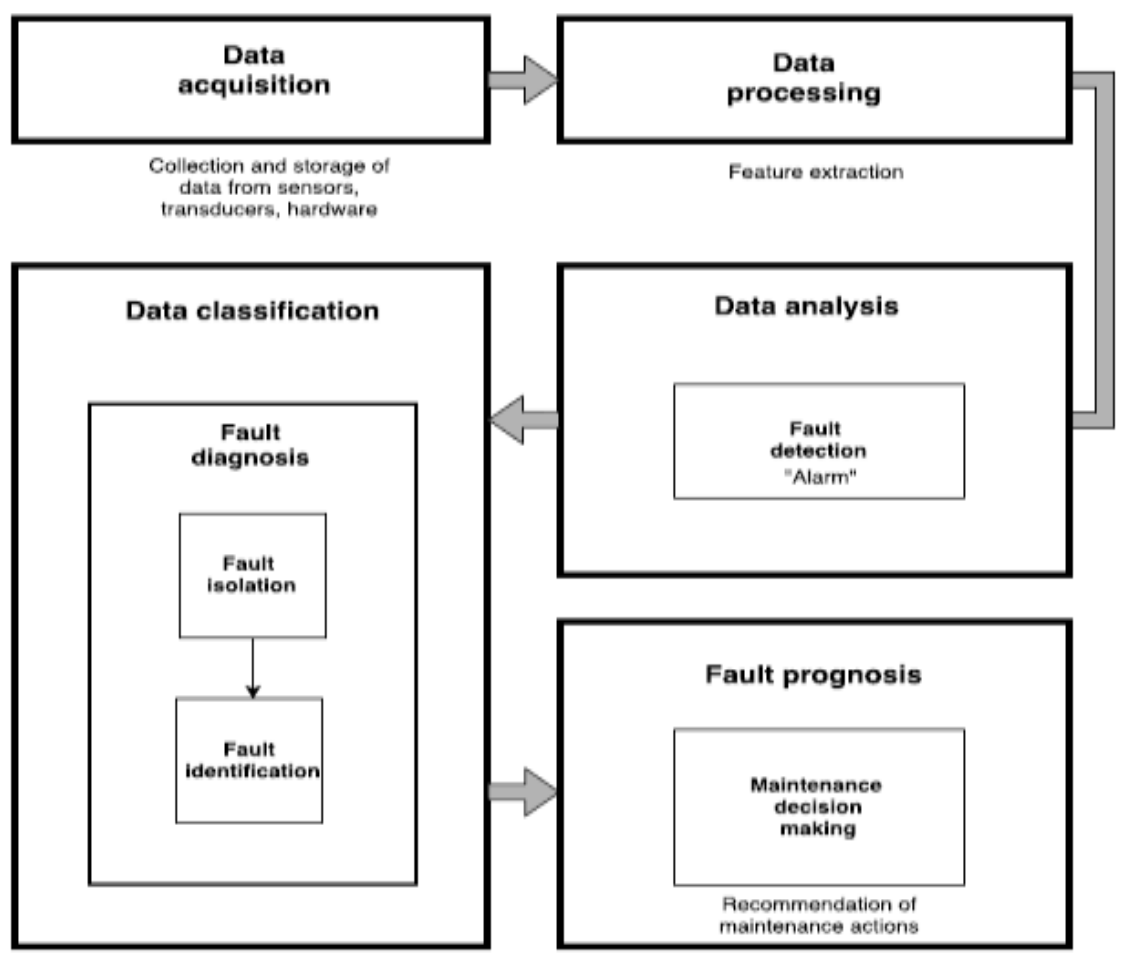

Figure 2: Flowchart summarizing the process of condition-based maintenance [6].

\section{CONDITION MONITORING TECHNIQUES}

Condition monitoring represents the advanced monitoring of a machine to allow predictive maintenance and thus the ability to detect an incipient fault before it causes an identifiable issue. The continuing push to develop diesel engine monitoring systems that can both monitor operating performance, and provide effective fault diagnostics and prognostics has led to continuing research interest regarding the development of monitoring technologies. This interest has resulted in the continued development of engine monitoring methods using both established and emerging engine monitoring technologies [11]. Therefore, the development of diesel engine fault diagnosis technology is very necessary to ensure operational safety, performance, reasonable maintenance, cost reduction, pollution prevention, and information collection. [12]. There are various techniques for condition monitoring and fault diagnosis of diesel engines, some of which will be introduced briefly below:

\subsection{Performance Parameter Diagnosis Technique}

The engine operation fundamental element is the combustion, other aspects associated with engine operation are in some way linked to combustion-related characteristics. Engine reliability is also directly linked to the combustion process as combustion directly affects the thermal and mechanical stresses, corrosion, and wear experienced by engine components [11]. Diesel engine performance parameters are uses in this method to get fault diagnosis by condition monitoring of the internal combustion engine operation, which is mainly determined by the degree of the combustion process that is affected by the thermal, mechanical and fluid aspects of each system [13]. Early techniques of cylinder pressure measurement involved the use of mechanical indicators which plotted the pressure-volume curve on paper [14]. Measurements of cylinder pressure provide the most direct means of analyzing the combustion process and indeed, have been a key tool in engine research and development for a long time [15]. Modern techniques of cylinder pressure measurement involve the use of piezoelectric sensors because are light, small and have a high-frequency response [16]. Parameters such as compression pressure, maximum firing pressure, indicated mean effective pressure, pumping mean effective pressure, maximum pressure rise rate, and other more complex thermodynamic properties are all given by cylinder pressure measurements thermodynamic parameters and cylinder pressure measurements for combustion diagnosis [17]. Nowadays these are typical characteristics of a modern engine indicating system, as the one schematically represented in Figure 3, which includes components suitable for measurements in diesel engines. In this scheme, the fuel injection line pressure is measured with a strain-gauge based sensor connected to an instrumentation amplifier, while the signal generated by a piezoelectric pressure sensor can be conditioned following two measurement procedures. In the first procedure, the incylinder pressure is obtained by employing a charge amplifier for conditioning the transducer signal [18]. 


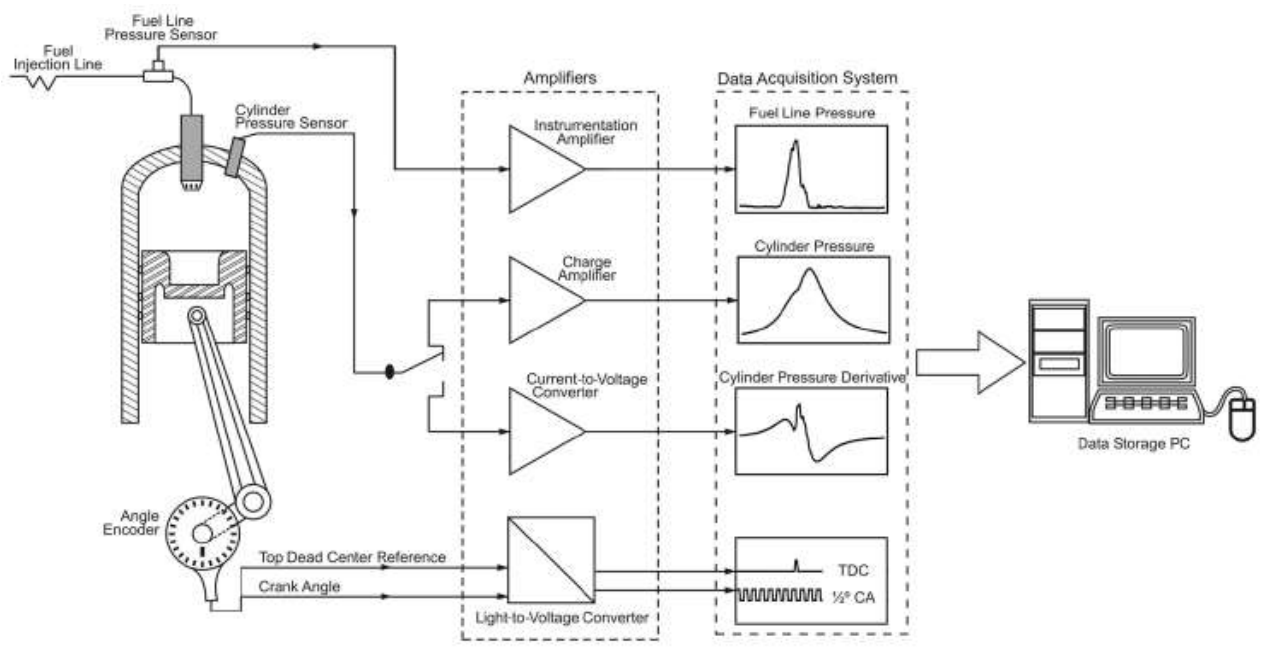

Fig. 3: A typical engine indicating measurement system [18].

Pressure data are indexed with the angular position of the crankshaft, concerning the compression TDC. Usually, the crankshaft angle position is determined with an optical angle encoder, which provides both one pulse per revolution in a channel used to establish the TDC angle reference, and 720 pulses per revolution in a second channel to determinate the instantaneous relative angle position. External pulse multipliers may also be available to improve the relative angular position resolution up to 3600 pulses per revolution. Each angle position pulse triggers a high-speed data acquisition system, which should be able to simultaneously acquire the signals provided by the conditioning amplifiers, collect the acquired data among multiple cycles for cycle averaging, and save it in a storage computer. In a CM context, cylinder and injection pressure measurements were used by Hountalas and Kouremenos [19] as input parameters that were used in a detailed thermodynamics based engine model to evaluate engine condition. In applying the method to a large two-stroke marine Diesel engine, the authors were able to diagnose a series of causes responsible for poor engine performance that could not be detected using conventional instrumentation. Hountalas et al. [20] proposed a methodology for evaluating the compression condition and identifying compression related faults in Diesel engines based on cylinder compression pressure measurements taken during motored operation. T. R. Lin et al. [21] presented the results of an experimental investigation on identifying the signal characteristics of a simulated incipient injector fault in a diesel engine using both in-cylinder pressure and acoustic emission (AE) techniques. R. Johnsson [22] proposed a non- linear model dependent on complex radial basis function (RBF) systems for the reproduction of in-cylinder pressure beat waveforms and showed mean powerful weight. D. T. Hountalas et al [23] used three methodologies developed to take into account the effect of changing the load during measurement and were applied to a two-stroke diesel engine. The results demonstrated the success of the three methodologies to adjust the engine required to ensure the uniform operation of the cylinder with a different load during measurement. Ahmed Al-Durra et al [24] described the preliminary results of a model-based estimation methodology to reconstruct the individual in-cylinder pressure traces of a multi-cylinder engine, relying on the engine crankshaft speed sensor measurement. The results, in terms of cylinder pressure traces reconstruction and calculated combustion metrics, show that the design is sufficiently accurate and robust to disturbances in the measured signals. In particular, the augmented estimator was able to remove the effect of the overlap to obtain an accurate pressure trace, which leads to an improved estimation of the pressure and IMEP during the entire engine cycle. L. Eriksson and A. Thomasson [25] presented a survey of the use of cylinder pressure sensors in internal combustion engine estimation and control. D. Vollberg et al [26] proved that the sensor characteristics are unaffected by testing the sensor over 20 million combustion cycles. In-cylinder pressure measurements in a Diesel engine include a lot of information on the condition of the engine and its combustion efficiency. This has its obvious drawbacks in that it requires obtrusive access to a cylinder head and whether the maintenance is carried out in the house or by a maintenance company, equipment owners are never happy to have holes drilled in their cylinders. Studies have shown that the use of an in-cylinder pressure transducer actually affects the cylinder pressure compared to a measurement taken unobtrusively and various studies have described how the air mixing varies throughout the cylinder during compression and combustion. Therefore taking the pressure at a single point does not provide an entirely accurate picture of the conditions throughout the entire cylinder. The conditions for the sensor are very extreme making a sensor life short, therefore increasing costs [27]. As direct measurements of the cylinder pressure are expensive and not suitable for measurements in vehicles on the road indirect methods that measure cylinder pressure have great potential value [22]. Indirect measurement of the cylinder pressure from diesel engines is possible using acoustic emission (AE) [28]. 


\subsection{Oil Analysis Diagnosis Technique}

Large diesel engines use these techniques already in widespread within the community. Oil analysis provides an idea of wear occurring within the moving parts via the type of debris contained within it. The oil sample is usually taken from the oil pan. Various techniques may be used in the analysis of oil as viscosity, spectral examination, flash point, and insoluble. (Viscosity) Determines the oil grade and whether its chemical structure has been altered in some way. This is usually measured in centistokes (CST) and is at a reference temperature of 40C. The test is usually a measurement of how long it takes the oil to ow through a standard orifice. The viscosity [29]. (Spectral Examination) Determines the wear metals amount, additives, silicone, and coolant within the oil. Using a spectrometer machine which is highly accurate and provides the reading in parts per million. For example, this test could be the discovery of Copper and Chromium within the information gathered from the oil. Copper is usually a sign of bearing and bushing wear, chromium would be associated with the piston rings, and would be caused by dirt coming through the air intake or broken rings. (Flash Point) Determines the lowest temperature at which the oil will ash, in other words, produces enough vapor to ignite when exposed to a source of ignition. A change in the ash point compared to the fresh oil ash point shows the presence of contaminants. (Flashpoint Insoluble) Determines the amount of insoluble material present in the oil testing gives an indication as to whether there is any fuel or solvent ingress [27]. The test consists of a centrifugal test where the oil is mixed with a heated agent and spun in a centrifuge. The insoluble materials gather at the bottom of the test tube and can then be indented and quantized. The test for insoluble is a good indication of how quickly the oil is oxidizing, gathering contaminants, and also how well the engine alteration system is working. This test can provide some indications that something may be wrong with the engine, but it can also indicate, simply that too long has been left between oil changes. Beck and Johnson [30] used ferrography to monitor particles present in the lubricant of a diesel engine. Since then there have been many reports on the application of ferrography and oil spectrometry to many kinds of diesel engines. M. Johnson and M. Spurlock [31] mentioned in their overview, tribological condition monitoring techniques, commonly referred to as oil analysis, were first used for condition monitoring in a systematic fashion by the railroad industry in the U.S.A. soon after the Second World War. Oil analysis techniques then developed rapidly and by the mid 1950's oil analysis methods were being used by the U.S. Navy to monitor jet engines. Oil analysis methods are now widely used to monitor hydraulic plants, gas turbines, reciprocating engines, gearboxes, and a host of other plants and are generally considered to be a mature technology with proven condition monitoring and fault diagnosis abilities. R. Jiang and X. Yan [32] highlighted the wide acceptance of oil analysis methods for engine monitoring specifically, by mentioning that oil analysis is the most widely used condition monitoring method for Diesel engines. Oil analysis methods were classified by R. Jiang and X. Yan [32] as belonging to one of three categories; concentration analysis, debris analysis methods, or lubricant health analysis methods.

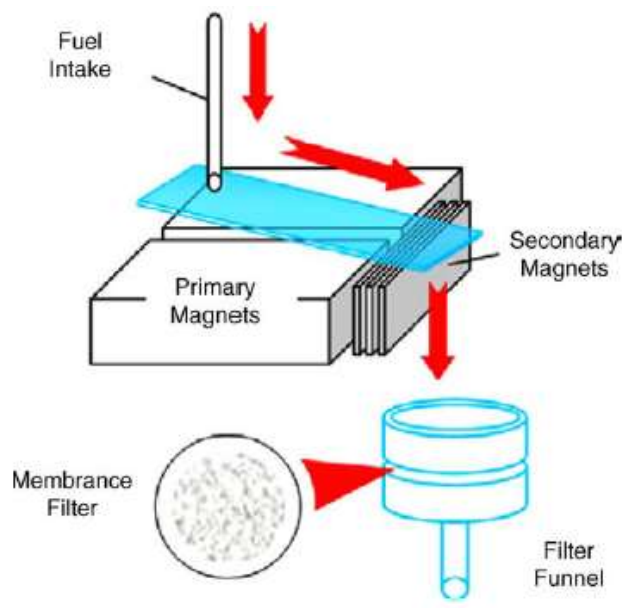

Fig. 4 Ferrograph Scheme [30].

S. D. Haddad [33] discussed the aims of concentration analysis and debris analysis methods to characterize the location and type of wear occurring, based on debris present in the lubricant with the most important parameters being quantity, size distribution, morphology, and composition. Lubricant health analysis aims to ascertain the condition of the lubricant itself by assessing lubricant qualities such as viscosity, neutralization number, contaminant levels, and the degree of oxidization. Specific, commonly used methods include magnetic plug inspection, blotter spot test, spectrographic analysis, ferrography, x-ray fluorescence, and thin-layer chromatography. Although Oil analysis methods are considered to be a mature technology, several recent investigations have been undertaken regarding their use in the automated fault detection system. V. Macian et al. [34] proposed a prototype fuzzy expert system for oil analysis based Diesel engine fault diagnosis.

Morgan et al. [35] Utilized a combination of the self-organizing map and the $\mathrm{K}$ means algorithm to classify potential faults. Also, they point out that the development of computer hardware and compact spectrometry equipment has "allowed on-line and 'pseudoon-line' oil analysis to be carried out on-board ships with a change in perspective from purely expert systems to more data-centric 
approaches". Y. Liu et al. [36] demonstrated an online oil analysis based monitoring for large marine diesel engines. It has been shown that the major limitations associated with the use of oil analysis-based techniques continue to be the predominant off-line nature of the analysis, time and expense associated with the collection and examination of samples, and the inability to monitor components or regions of the engine that are not subject to lubricant flow. I.R. Taylor and G.P. Evans [37] measured the instantaneous frictional force acting on the ring-pack of a single-cylinder diesel engine using a floating-liner technique. Figure (5) shows the results obtained for three oils of different viscosity at constant engine speed and liner temperature.

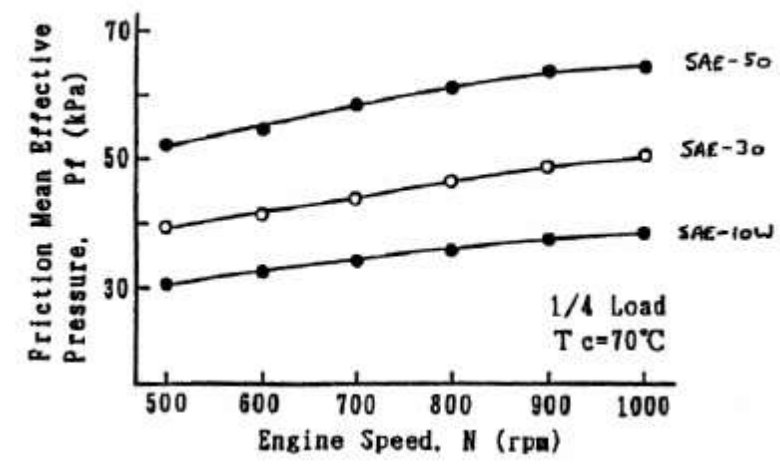

(a) Overall frictional loss.

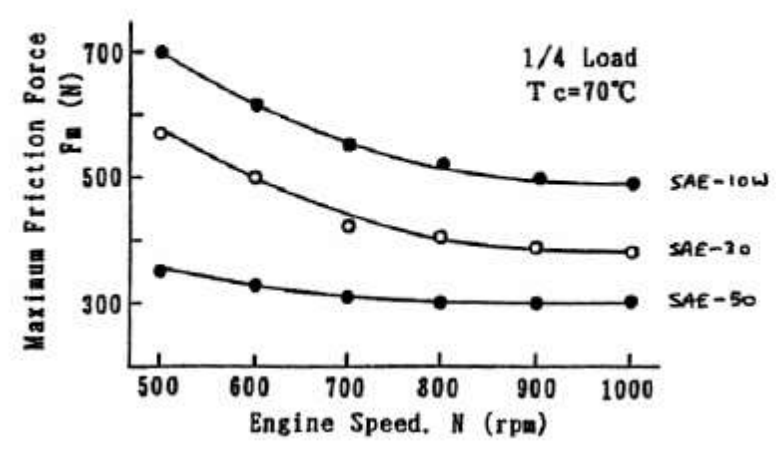

(b) Peak friction force.

Figure 5: Variation of friction characteristics with engine speed [37].

The friction force incurred at mid-stroke was found to increase with oil viscosity whilst the peak frictional force occurring just after TDC firing reduced. A measure of frictional loss was obtained through summation of the area under the friction curve. With increasing engine speed the frictional loss increased, Figure 5a, and the value of peak friction decreased, Figure 5b, this was observed to be consistent for all three oil viscosities.

\subsection{Vibration Monitoring Diagnosis Technique}

Vibration monitoring is the most widely used condition monitoring technique, where the vibrations of the machine are analyzed to determine incipient faults. Overall vibration monitoring can be used to detect faults such as mechanical looseness, rotating or reciprocating imbalance, shaft misalignment, bearing damage, cavitation, and electrical faults it is popular, as almost every machine or process will produce some form of vibration. It is being used today in the industry quite successfully. Vibration signals can be used to display frequency content as well as simple peak or root mean squared (RMS) values. Whilst overall vibration data is commonly taken to monitor for routine faults it is now clear that overall vibration monitoring does not hold a good level of condition monitoring data which it was once thought it did. Typically in industry, the vibration sensor system picks up the total vibration level, amplifiers it, time averages it, and records it as a single value. Whilst overall vibration monitoring can detect these faults, it cannot distinguish between them because there is no frequency content in the data. Frequency content is required for fault diagnosis, this is where spectral vibration monitoring has the advantage in terms of diagnosis and how early it can detect a fault. Spectral vibration monitoring allows the values of individual frequency peaks within a vibration frequency spectrum to be trended as individual parameters [27]. However, vibration monitoring applications to internal combustion and diesel engines have remained rather limited, essentially because of the complexity of the vibration signals see Figure 6 [38].

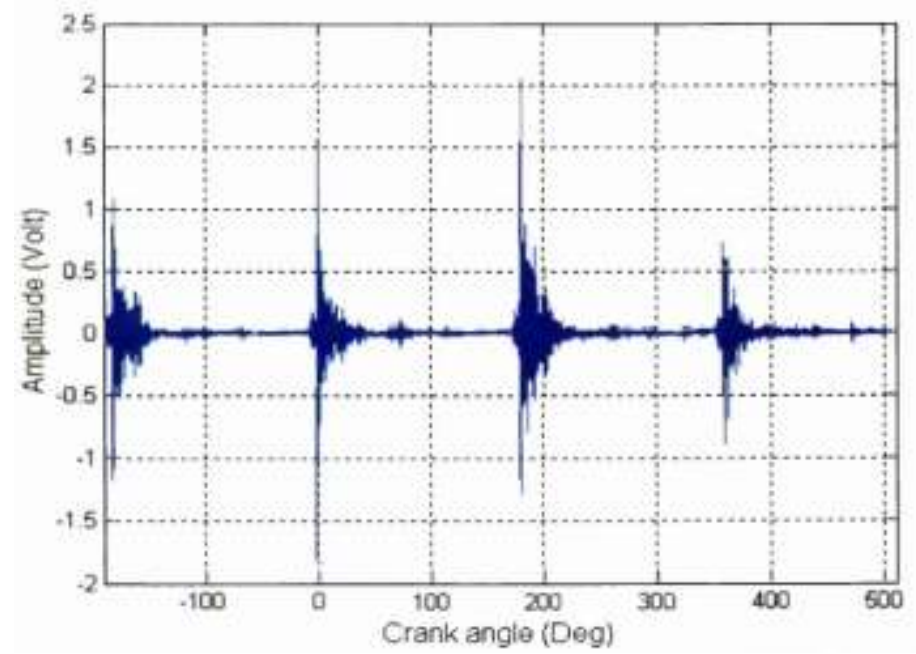

Figure 6: Engine body vibration [38]. 
J. Antoni et al. [39] investigated the "rocking and twisting of the engine block on its supports due to the action of inertial forces" and the impacts due to clearances associated with the crankshaft and piston pin bearings as other sources of vibration in engines. They emphasized when they point out that the impulse response for a typical engine structure lasts for a few milliseconds, which for an engine operating at $1500 \mathrm{rpm}$, translates to a crank-angle window that is greater than $10^{\circ}$ in length. B. A. Badawi et al. [40] investigated and focus on the development and application of source separation techniques using of a technique whereby vibration signals recorded from a single accelerometer on a small single-cylinder Diesel engine were separated using segmentation independent component analysis and vibration due to valve operation, fuel injection, combustion and piston slap were identified. Also, identified gas dynamics as contributing to engine vibration. X. Liu and R. B. Randall [41] studied source separation issues and applied blind source separation techniques to vibration data recorded from a small four-cylinder Diesel engine operating under both normal and faulty conditions. Reasonable results were obtained for fuel injection, piston slap, and combustion pressure variations. X. Liu et al. [42] reported that three sources; interpreted as piston slap, cylinder pressure change due to piston motion and cylinder pressure oscillation due to combustion also reported that recovered pressure could be considered as two distinct sources a low-frequency component associated with piston movement and a high-frequency component associated with combustion. Brian R et al. [43]: Highlighted the appearance of various signal features using a combination of measures that relate to a broad range of diesel engine faults such as cylinder liner scuffing, piston slap, injection-related faults, and valve-related faults, worn piston rings, collapsed lifter and incorrect valve-lash. G. Chandroth et al. [44] used three different feature extraction techniques to develop an artificial neural network-based Diesel engine fault diagnosis system. The three feature extraction techniques; domain expertise, wavelet analysis, and principal components analysis were used to detect injector related faults and leaking valves. And they described the three feature extraction techniques as exhibiting a high degree of accuracy. Jia- shan Huang et al. [45] and Yu-Long Zhan [46] studied the diesel engine fault diagnosis using Discrete Hidden Markov Model (DHMM) and Principal Component Analysis (PCA), the practical application results showed that the method proposed for diesel engine fault diagnosis that can be achieved with high accuracy. K.Jafarian et al. [47] used a vibration analysis to detect and classify faults that have arisen due to poppet valve clearance and incomplete combustion which is sometimes called the imbalance phenomenon of an internal combustion engine. So, they used four accelerometers on the OHV engine body to record the vibration signals. The data acquisition was then investigated using PCA technique. In the end, they efficiently classify and detect faults .S. Liu et al. [48] Proposed a simple technique for detecting primary engine valve malfunctions by measuring vibration signals on the cylinder head. The characteristics of the vibration signal are analyzed, indicating that its time domain and frequency domain properties are both useful for motor diagnostics while cycle-by-cycle variation appears to be a defect. The experimental results showed that the proposed technique is feasible, effective, and simple to implement. K. Jafariana et al. [49] investigated clearance of engine valve and engine misfire to fault detection in the internal combustion engine, using the vibration data captured under different experimental circumstances and four sensors. The application of the Fast Fourier Transform (FFT) was proposed as a feature extraction methodology which leads to the extraction of 16 features. Proposed the statistical approach and the Artificial Neural Networks (ANN) to predict if the motor works healthily based on the selected features and, if not, what kind of faults is in the engine. Compared the results proves the validity of the proposed methods and highlights their superiorities. Signal processing approaches can be in terms of different vibrations it is classified into three major groups, the first group includes the approach with an analysis of the time domain, such as the work done by Heng and Nur [50]Martin and Honarvar [51], Leibovsky, his colleagues [52], Ragul'skis and others [53]. Second group includes the works that are considered Frequency field analysis, such as Courrech [54], Miao et al. [55] W.Miao et al. [56]. The third group uses time-frequency analysis, Among Ping and Yam [57], Wang and Hussein [58]. The Frequency domain analysis is the most used approach it has proven its effectiveness and its unwanted calculation in Provide basic information that leads to salient frequency band features [59]. Recently, engine monitoring and error detection methodologies significantly improved.

\subsection{Instantaneous Angular Speed Diagnosis Technique}

Instantaneous Angular Speed (IAS), is a speed measurement of the engine crankshaft, the speed of which will vary as cylinders fire and subsequently compress. Using sensors such as a wheel encoder the speed change is measured and can detect faults associated with the fuel injection and combustion systems. Some of the latest techniques allow the fault to be located to a particular cylinder, however, all of the IAS techniques based on Diesel engines as yet allow the locating of faults but do not allow for the diagnosis of faults [27]. Techniques involving measurements of angular speed have been used across a broad range of control and CM applications however a great deal of research interest has previously been generated regarding the use of these techniques in ECM applications. ECM techniques utilizing crank-angle measurements are based on the measurement of the small variations in angular speed and acceleration experienced by the crankshaft due to the rapid variations in-cylinder pressure occurring in the individual cylinders during engine operation. The direct relationship between crank-angle speed fluctuations experienced by the crankshaft and the variations in-cylinder pressure has been used to indirectly measure engine torque and cylinder pressure [11].

Tian R Lin et al. [60] Presented the IAS analysis technique for the estimation of engine power output and condition monitoring of diesel engines. It was shown that IAS analysis can provide useful information about engine speed variation caused by the 
changing piston momentum and crankshaft acceleration and can also be used for engine power output estimation at various engine-operating (either normal or faulty) conditions. T .S. Brown and W. S. Neill [61] demonstrated a technique to indirectly measure individual cylinder pressures of a diesel engine based on crank-angle speed fluctuations. The analysis of crank-angle speed data was categorized as being either model-based or library-based. S. J. Citron et al. [62] developed a four degree-offreedom dynamic model of the engine and drive-train was and the measured crank-angle speed data used as input to calculate total torque and pressure torque fluctuation waveforms as well as the pressure torque, and cylinder pressure waveforms. Charles et al. [63]: Extended the IAS technique further for condition monitoring and fault diagnosis of diesel engines with a large number of cylinders. By presenting the IAS waveform in a polar coordinate system, they demonstrated that the IAS waveform can be utilized to detect and identify the faulty (misfiring) cylinder of two relatively large multi-cylinder (16 and 20 cylinders, respectively) engines. J. Yang et al. [64]: Presented a dynamic model that was used to generate instantaneous angular speed fluctuation ratio and instantaneous angular speed waveforms. During the experimental phase of the investigation, a fault diagnosis method using the IASFR was used to detect a fuel leak in one of the high-pressure fuel lines in a small four-cylinder engine. Taraza et al. [65] investigated the amplitude change of order components of IAS waveforms of two diesel engines and correlated the amplitude of the lowest major harmonic order (order 2 for a four-cylinder engine and order 3 for a six-cylinder engine) of IAS spectra to that of the gas pressure torque produced by the engine combustion. They also illustrated that phases of the three lowest order components of the IAS spectrum could be utilized to identify the faulty cylinder of a diesel engine. F. V. Tinaut et al. [66] pointed out two main approaches used for crank-angle based detection of a misfire. This approach is described as being able to correctly diagnose faults in engines operating under transient conditions and at higher engine speeds whilst requiring less calculation capacity compared to other model-based methods. J. Franco et al. [67] presented is a real-time engine brake torque estimation model whose input is the instantaneous engine speed. This model is separated into steady-state and transient torque estimations. From the instantaneous engine speed signal, both the crankshaft torsional due to the power stroke and mean engine speed were estimated in real-time. Validation of the engine brake torque estimation model showed that the model was able to estimate torque within $72 \%$ of rated torque. Douglas et al. [68] applied both acoustic emission (AE) and IAS techniques for the online power estimation of two large marine diesel engines. They found that the calculated standard deviation of IAS waveforms in each engine cycle changes accordingly to the loading condition of the marine engines under test. R. Johnsson [69] developed an indirect method based on the crankshaft speed fluctuations combined with neural networks to predict the maximum cylinder pressure. Fluctuations of the speed were measured on inline diesel engine a 6cylinder at 9 speed-load-combinations. The results from the neural network were found to be better and the TDC-position for all 6 cylinders was determined within \pm 0.1 degree crank angle at 95\% confidence interval. Recently Li et al. [70] Presented a comprehensive discussion for optimizing IAS measurements and provided a detailed IAS error analysis. Gu et al. [71] developed a theoretical model for noise reduction of IAS signals by employing a combined FFT and Hilbert transform. They then implemented the method to reduce the noise in IAS data acquisition and its influence on the IAS estimation and fault diagnosis of a rotor-shaft system. Cedric Peetersa et al. [72] reported the available knowledge regarding vibration-based speed estimation techniques. They also reviewed some of the most commonly used techniques by means of performance comparison of seven-speed estimation methods on three different experimental data sets. The resulting speed estimation data of all tested methods is made publicly available such that it can help in forming a benchmark for future speed estimation methods.

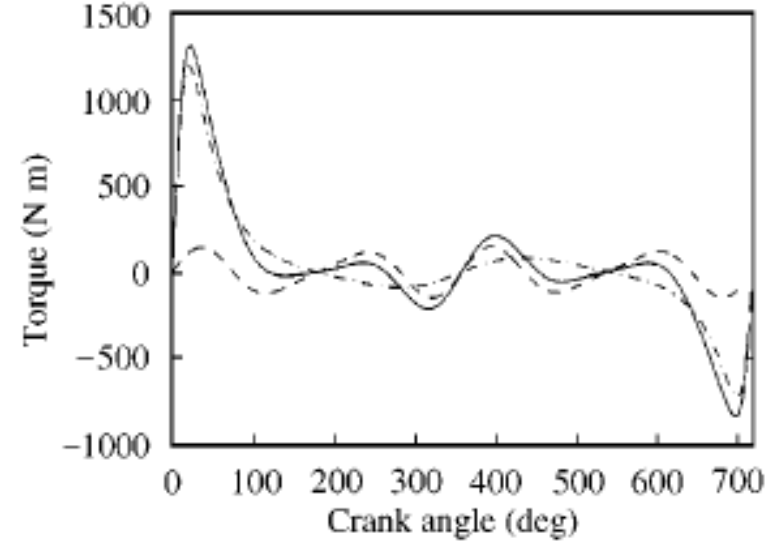

(a) single-cylinder, 4-stroke engine

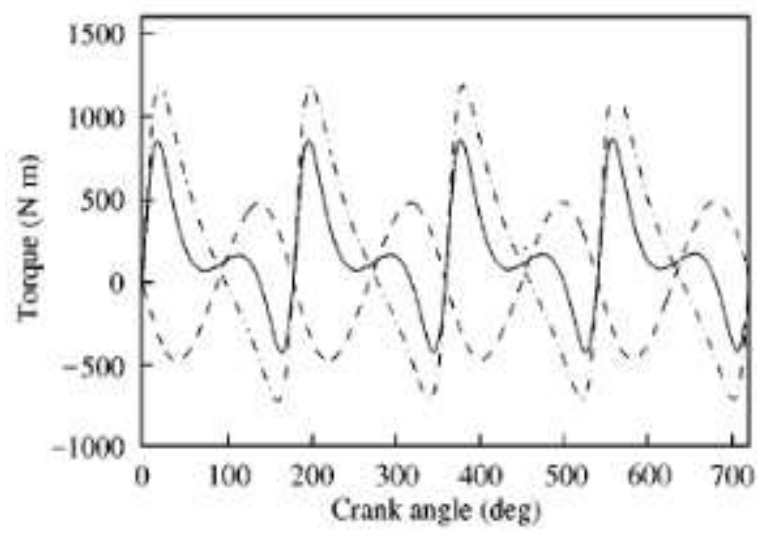

b) 4-cylinder, 4-stroke engine

Figure 7: Modelled torque behavior, both (a) and (b) at 1000 RPM, Yang et al [15].

\subsection{Acoustic Condition Monitoring Diagnosis Technique}

Acoustic emission is a category of phenomena through which transient elastic waves are generated through the rapid release of energy from a source or local sources within a material or a transient elastic wave. Other terms that have been used in AE literature include (1) stress wave emission, (2) micro-seismic activity, and (3) emission or acoustic emission with other qualifying 
modifiers [73]. Z. Jiang et al. [74] developed an effective approach to detect and diagnose ICE valve Train clearance based on the vibration signal measured on engine cylinder heads. Experimental results proved that the selected feature is really perfect for this Error detection, feature extraction results are accurate enough. W Abdu et al. [75] Presented the diesel fuel injection monitoring results online to improve performance. It is concluded that the injection device provides a suitable test site to check the injection process in isolation from other AE noises associated with engine operation. D. P. Lowe et al. [76] Presented an experimental investigation into the detection of excessive diesel knock using acoustic emission (AE) signals. It was additionally discovered that the AE sensor position is basic. The AE sensor situated on the square of the engine obviously related data concerning the degree of diesel thump happening in the engine whist the sensor situated on the leader of the engine gave no sign concerning diesel knock seriousness levels. A. I. Alahmer et al. [77] presented a fault detection method for a SI engine at variable speeds using the acoustic signal technique. The exploratory outcomes demonstrated that: 1) the SPL sound pressure level because of fizzle breakdown increments as the engine speed diminishes; 2) at low frequencies the distinction between the two estimations of SPL is extremely little thought about at high frequencies; 3) the bent shape for SPL follows the state of the force delivered from the engine. D. Ning et al. [78] proposed a method instantaneous frequency analysis. Utilizing the proposed time-recurrence model, we can recognize the motor condition and decide anomalous sound delivered by faulty. N. H. Pontoppidan [73] investigated condition monitoring of large diesel engines from acoustic emission signals. With the occasion arrangement structure, it is demonstrated that non-stationary condition observing can be accomplished. B. Dykas and J. Harris [80] presented an experimental study of the application of acoustic emission sensor (AE) was applied to monitor the operating status of internal fuels for fuel, diesel, and health. A set of digital signal processing techniques have been drawn from literature, adapted, and applied.
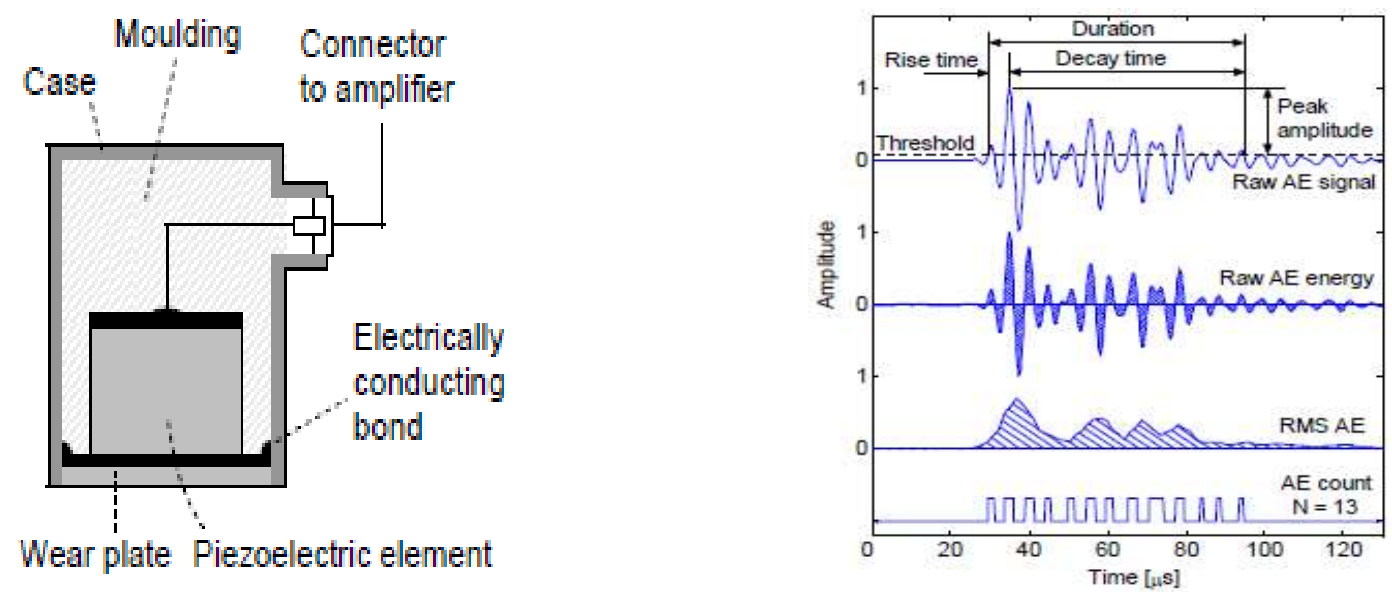

Figure 8: Schematic of an AE sensor [79].

Figure 9: Typical time-domain parameters extracted from AE signals [79]

Acoustic emission signals of the sensor installed on the engine, it was able to distinguish between load conditions and the failed injector, but no significant increases in the removal of the large final bearing from acoustic emission signals were identified. S. Putwattana and P. Nivesrangsan [81] Investigated injector operation used in the petrol engine using acoustic emission (AE) signals. It is proven that $\mathrm{AE}$ signal could be used to investigate various parameters that are related to various simulated conditions with no fuel and fuel injection such as time difference between two main events, delay time and amplitude of signals. J. A. Steel et al. [82] Investigated the characteristics of AE wave transmission around and through the cylinder head of a small four-stroke fuel injection diesel engine. The results can be used to reconstitute the timing and amplitude of the AE emitted at the source which enables much more focused monitoring of specific components and processes identified in the signals. Elamin and Fathi [83] focused on the possibility of using AE signals to monitor the fuel injector and oil condition. A comparison between signals and measurement of the oil condition showed both provided useful information about the lubrication processes. Simulation and experimental work have demonstrated the capability of this technique to detect lubrication related faults and irregular lubrication variability between the engine's cylinders. Elghamry and Mohamed Hussein [84] devised and developed a method using two diesel engines of the differing size of estimating the internal combustion engine power. This method involved reconstructing the cylinder pressure using only the AE signal from a sensor mounted on the surface of the cylinder block and represented another important potential use of AE monitoring. Nivesrangsan et al. [85] used a technique that they call "spatial reconstitution" to reconstruct the time series due to sources at a set of given locations from the synchronous record of AE at a sensor array. They found the attenuation factors for injector events to be similar to those measured from the simulated sources, but those for exhaust valve-opening showed a relatively poor correlation. They attributed this difference to variation in the actual source position during valve opening and also variable transmission though the multiple, moving interfaces in the cam, pushrods, and rockers. A technique pioneered by Lim et al. [86] used a ray firing procedure to model the transmission of rays both across the surface and 
through the interior of a complex solid. The approach considers the attenuation to be related to the AE path length and uses a virtual sensor to collect all rays arriving within a given extinction time, cumulating the energy arriving from each ray, modified according to its path length and number of reflections. The results of the computational simulation gave good agreement with measurements made on a cylinder block and various other simple cast iron objects.

\section{CONCLUSION}

Detecting defects in its early stages can help avoid bigger and more serious mistakes. Machine condition monitoring is divided into three phases, fault detection, fault diagnosis, and fault prognosis. Pressure measurements can be effective at assessing how well an engine is operating. But this has its obvious drawbacks in that it requires obtrusive access to a cylinder head, equipment owners are never happy to have holes drilled in their cylinders. Studies have shown that therefore taking the pressure at a single point does not provide an entirely accurate picture of the conditions throughout the entire cylinder. A sensor life short, therefore increasing costs. Indirect measurement of the cylinder pressure from diesel engines is possible using acoustic emission. Oil analysis provides an idea of wear occurring within the moving parts via the type of debris contained within it. The oil sample is usually taken from the oil pan. the major limitations associated with the use of oil analysis-based techniques continue to be the predominant off-line nature of the analysis, time and expense associated with the collection and examination of samples, and the inability to monitor components or regions of the engine that are not subject to lubricant flow. Vibration monitoring is the most widely used condition monitoring technique, where the vibrations of the machine are analyzed to determine incipient faults. Overall vibration monitoring can be used to detect faults such as mechanical looseness, rotating or reciprocating imbalance, shaft misalignment, bearing damage, cavitation, and electrical faults it is popular, as almost every machine or process will produce some form of vibration. It is being used today in the industry quite successfully. Typically in industry, the vibration sensor system picks up the total vibration level, amplifies it, time averages it, and records it as a single value. Vibration monitoring can detect these faults, it cannot distinguish between them because there is no frequency content in the data. Vibration monitoring applications to internal combustion and diesel engines have remained rather limited, because of the complexity of the vibration signals.

\section{REFERENCES}

[1] Flett, J. Bone and G. M., "Fault detection and diagnosis of diesel engine valve trains," Mechanical Systems and Signal Processing, vol. 72-73, pp. 316-327, May 2016.

[2] S. Allam, M .Abdo and M. Rabie, "Diesel Engine Fault Detection Using Vibration and Acoustic Emission Signals," International Journal of Advances in Scientific Research and Engineering (ijasre), vol. 4, no. 12, p. 86, 2018. https://doi.org/10.31695/IJASRE.2018.33005.

[3] E. Ftoutou, M. Chouchane, N. Besbès and R. Ouali, "Detection of diesel engine misfire by vibration analysis," in Congrès Tunisien de Mécanique COTUM'08, Hammamet, 2008.

[4] Y. Alhouli, A. Alkhaledi, A. Alzayedi, M. Alardhi and A. Abed, "Study of Diesel Engine Vibration Condition Monitoring ," Global Journal of Researches in Engineering, vol. XV, pp. 37-44, 2015

[5] P.Arques , "Parametrical Assessment of Damage for Diesel fuel Injection Systems," Seminar on Diesel Fuel Injection System of Institution of Mechanical Engineers. Birmingham Grande Bretagne, 1989.

[6] J.L.Neset, "Condition Monitoring of Mechanical Equipment Using Bilinear Modeling of Vibrations," Master of Science in Industrial Cybernetics, 2018.

[7] J. S. Rao, "Vibratory Condition Monitoring of Machines," CRC Press/Narosa Pub, 2000.

[8] A. R. Mohanty , "MACHINERY CONDITION MONITORING," principles and practices CRC PRESS, 2017.

[9] R. B. Randall, "Vibration-based Condition Monitoring," Industrial, Aerospace and Automotive Applications, pp. 1-23, 2011.

[10] A. K. Jardine,D. Lin and D. Banjevic, "A review on machinery diagnostics and prognostics implementing condition-based maintenance," Mechanical Systems and Signal Processing, vol. 20, no. 1483-1510, 2005.

[11] D.Patrick Lowe, "Characterisation of Combustion Related Acoustic Emission Sources for Diesel Engine Condition Monitoring," PhD thesis, Queensland University of Technology, p. 11, 2013.

[12] Z. Wang, "Study on Fault Diagnosis of Fuel Injection Based on Vibration Signal Analysis of High-pressure Fuel Injection Pipe," Applied Physics Research CCSE, vol. 1, pp. 102-106, 2009. 
[13] A.Vencl and A. Rac, "Diesel Engine Crankshaft Journal Bearings Failures: Case Study," ResearchGate, 2014.

[14] C. A. Amann, "Cylinder-Pressure Measurement and its Use in Engine Research," SAE Technical, 1985.

[15] J. A. Steel and R. L. Reuben, "Recent Developments in Monitoring of Engines using Acoustic Emission," Journal of Strain Analysis, Vol. , No 1, , vol. 40, pp. 45-57, 2005.

[16] Andrew L. Randolph, "Methods of Processing Cylinder-Pressure Transducer Signals to Maximise Data Accuracy," SAE Technical Paper, no. 0148-7191, 1990.

[17] F. Payri, J. M. Lujan, J. Martin and A. Abbad, "Digital Signal Processing of In-Cylinder Pressure for Combustion Diagnosis of Internal Combustion Engines," Mechanical Systems and Signal Processing, no. 1767-1784, p. $24,2010$.

[18] André V. Bueno1, José A. Velásquez and Luiz F. Milanez, "Internal Combustion Engine Indicating Measurements," InTech, vol. 1 , no. 978-953, p. 51, 2012.

[19] D. Watzenig, M. S. Sommer and G. Steiner, "Engine State Monitoring and Fault Diagnosis of Large Marine Diesel Engines," Elektrotechnik \& Informationstechnik, no. 173-179, 2009.

[20] D. T. Hountalas, G. C. Mavropoulos and G. Kourbetis, "Experimental Investigation to Develop a Methodology for Estimating the Compression Condition of DI Diesel Engines," Energy Conversion and Management, no. 1-18, p. 47, 2006.

[21] T. R. Lin, A. C. C. Tan and J. Mathew, "Condition Monitoring and Diagnosis of Injector Faults in a Diesel Engine Using In Cylinder Pressure and Acoustic Emission Techniques," in 14th Asia Pacific Vibration Conference APVC, The Hong Kong Polytechnic University, 5-8 December 2011.

[22] R. Johnsson, "Cylinder pressure reconstruction based on complex radial basis," Mechanical Systems and, no. 1923\{1940, p. 20, 2006.

[23] D. T. Hountalas,R. G. Papagiannakis,G. Zovanos and A. Antonopoulos, "Comparative evaluation of various methodologies to account for the effect of load variation during cylinder pressure measurement of large scale two-stroke diesel engines," Applied Energy, vol. 113, no. 1027-42, 2014.

[24] Ahmed Al-Durra, Lisa Fiorentini, Marcello Canova and Stephen Yurkovich, "A Model-Based Estimator of Engine Cylinder Pressure Imbalance for Combustion Feedback Control Applications," American Control Conference on O'Farrell Street, San Francisco, CA, USA, vol. 978, no. 14577, 2011.

[25] Lars Eriksson and Andreas Thomasson, "Cylinder state estimation from measured cylinder pressure traces - A Survey," Preprints of the 20th World Congress The International Federation of Automatic Control, 2017.

[26] Dennis Vollberg, DennisWachter, Thomas Kuberczyk, and Günter Schultes, "Cylinder pressure sensors for smart combustion control," J. Sens. Sens. Syst, vol. 8, p. 75-85, 2019.

[27] D. J.Moore, PhD thesis,Faculty of Engineering and Physical Sciences, 2013.

[28] M. El-Ghamry, J. Steel, R. Reuben, and T. Fog, "Indirect measurement of cylinder pressure from diesel engines using acoustic emissions," Mechanical and Signal Processing, vol. 19, no. 751\{765, p. 4, 2005.

[29] M. Barnes, "Oil viscosity - how it's measured and reported," Published online at: http://www.machinerylubrication.com/Read/411/oil-viscosity, 2002.

[30] Beck, J. Johnson, "The Application of Analytical Ferrography and Spectroscopy to Detect Normal and Abnormal Diesel Engine Wear," SAE paper, no. 841371, 1984.

[31] M.Johnson and M.Spurlock, "Strategic Oil Analysis: Systems, Tools and Tactics," Tribology and Lubrication Technology, p. $28,2009$.

[32] R.Jiang and X.Yan, Condition monitoring of Diesel Engines, Verlag London: Springer, 2008.

[33] S. D. Haddad, Condition Monitoring and Fault Diagnosis in Diesel Engines, England: Ellis Horwood Limited, 1984.

[34] V. Macian, B. Tormos, A Sala and J. Ramirez, "Fuzzy Logic-Based Expert System for Diesel Engine Oil Analysis 
Diagnosis," Insight, vol. 48, no. 462-469, p. 8, 2006.

[35] I.Morgan, H.Liu, G. Turnbull and D.Brown, "Predictive Unsupervised Organisation in Marine Engine Fault Detection," Proceedings of the International Joint Conference on Neural Networks, IJCNN, no. 1-6, 2008.

[36] Y. Liu, Z. Liu, Y.Xie and Z. Yao, "Research on an On-Line Wear Condition Monitoring System for Marine Diesel Engine," Tribology International 33, no. 829-835, 2000.

[37] I.R.Taylor. and G.P.Evans, "In-situ piston measurements," Proc. of the IMechE Part J: Journal of Engineering Tribology, vol. 218(3), pp. 85-200, 2004.

[38] A. S. Albarbar, "The Acoustic Condition Monitoring of Diesel Engines," phd thesis, 2006.

[39] J. Antoni, J. Daniere, and F. Guillet, "Effective Vibration analysis of IC Engines Using Cyclostationarity," Methodology for Condition Monitoring. Journal of Sound and Vibration, no. 815-837, p. 257, 2002.

[40] B. A. Badawi, M. A. Shahin, M. Kolosy, S. A. Shedied and A. Elmaihy, "Identification of Diesel Engine Cycle Events using Measured Surface Vibration," SAE Technical Paper, no. 32-0097, 2006.

[41] X. Liu and R. B. Randall, "Blind Source Separation of Internal Combustion Engine Piston Slap from Other Measured Vibration Signals," Mechanical Systems and Signal Processing, no. 1196-1208, p. 19, 2005.

[42] X. Liu, Robert B. Randall and J. Antoni, "Blind Separation of Internal Combustion Engine Vibration Signals by a Deflatation Method," Mechanical Systems and Signal Processing, no. 1082-1091, 2008.

[43] Brian R. Long and Kathy D. Boutin, "Enhancing the Process of Diesel Engine Condition Monitoring," Fall Technical Conference, 1996.

[44] G. Chandroth, A. J. Sharkey and N. E. Sharkey, "Vibration Signatures, Wavelets and Principal Components Analysis in Diesel Engine Diagnostics," Proceedings of Marine Technology ODRA, 1999.

[45] Jia-shan Huang and Ping-jun Zhang , "Fault Diagnosis for Diesel Engines Based on Discrete Hidden Markov Model," Second International Conference on Intelligent Computation Technology and Automation, vol. 358, 2009.

[46] Yu-Long Zhan,Zhu-Bin Shi, Theingi Shwe and Xiao-Zhong Wang, "Fault Diagnosis Of Marine Main Engine Cylinder Cover Based," International Conference on Machine Learning and Cybernetics, Vols. 19-22, 2007.

[47] K.Jafarian,M Darjani and Z Honarkar, "Vibration Analysis for Fault Detection of Automobile Engine Using PCA Technique," International Conference on Control, Instrumentation, and Automation (ICCIA), no. 978-1-4673, 2016.

[48] S. Liu, F. Gu and A Ball, "Detection of Engine Valve Faults by Vibration Signals Measured on The Cylinder Head," IMechE, vol. 220, 2006.

[49] K. Jafariana et al., "Misfire and valve clearance faults detection in the combustion engines based on a multi-sensor vibration signal monitoring," Elsevier Ltd, vol. 128 , no. 527-536, 2018.

[50] R. Heng, M.J.M. Nor, "Statistical analysis of sound and vibration signals for monitoring rolling element bearing condition," Appl. Acoust, vol. 51, no. 211-226, pp. 1-3, 1998.

[51] H. Martin, F. Honarvar, "Application of statistical moments to bearing failure detection," ScienceDirect, vol. 1, no. 67-77, p. 44, 1995.

[52] G. Lipovszky, K. Sólyomvári, G. Varga, "Vibration testing of machines and their maintenance," Elsevier Science, 1990.

[53] K.M. Ragul'skis, A.G.I.U. IUU rkauskas, E.I. Rivin, "Vibration of bearings, CRC Press," 1989.

[54] J. Courrech, "Envelope analysis for effective rolling-element fault detection-fact orfiction?," Up Time Magazine, vol. 8, p. 14-17, 2000.

[55] Q. Miao, L. Cong, M. Pecht, "Identification of multiple characteristic components with high accuracy and resolution using the zoom interpolated discrete Fourier nsform," Measur. Sci. Technol, vol. 5, no. 055701, p. 22, 2011. 
[56] Q. Miao, M. Azarian, M. Pecht, "Cooling fan bearing fault identification using vibration measurement," Prognostics and Health Management (PHM) IEEE, 2011.

[57] Y. Peng, R. Yam, "Wavelet analysis and envelope detection for rolling element bearing fault diagnosis - their effectiveness and flexibilities," J. Vibr. Acoustics, vol. 123, p. 303-310, 2001.

[58] W. Wang, B. Hussin, "Plant residual time modelling based on observed variables in oil samples," J. Operational Res. Soc. , vol. 6, p. 789-796, 2009.

[59] Z. Gan, M.-B. Zhao, T.W. Chow, "Induction machine fault detection using clone selection programming," programming, Expert Syst. Appl, vol. 4, p. 8000-8012, 2009.

[60] Tian R Lin, Andy CC Tan, Lin Ma and Joseph Mathew, "Condition monitoring and fault diagnosis of diesel engines using instantaneous angular speed analysis," J Mechanical Engineering Science, pp. 1-12, 2014.

[61] T.S.Brown and W. S.Neill, "Determination of Engine Cylinder Pressures from Crankshaft Speed Fluctuations," SAE Technical Paper, no. 920463, 1992.

[62] S. J. Citron, J.E. O’Higgins and L. Y. Chen, "Cylinder by Cylinder Engine Pressure and Pressure Torque Waveform Determination Utilizing Speed Fluctuations," SAE Technical Paper , no. 890486, 1989.

[63] Charles P, Sinha JK and Gu F, "Detecting the crankshaft torsional vibration of diesel engines for combustion related diagnosis," J Sound Vib, vol. 1171-1185, p. 321, 2009.

[64] J. Yang, L. Pu, Z. Wang, Y. Zhou and X.Yan, "Fault Detection in Diesel Engine by Analysing the Instantaneous Angular Speed," Mechanical Systems and Signal Processing, no. 549-564, p. 15, 2001.

[65] Taraza D, Henein NA and Bryzik W, "The frequency analysis of the crankshaft's speed variation: a reliable tool for diesel engine diagnosis," ASME J Eng for Gas Turbines Power, vol. 123, p. 428-432, 2001.

[66] F. V. Tinaut, A. Melgar, H. Laget and J. I. Dominguez, "Misfire and Compression Fault Detection Through the Energy Model," Mechanical Systems and Signal Processing, no. 1521-1535, p. 21, 2007.

[67] J. Franco, M. A. Franchekb, K Grigoriadis, "Real-time brake torque estimation for internal combustion engines," Mechanical Systems and Signal Processing, no. 338-361, p. 22, 2008.

[68] Douglas RM, Steel JA, Reuben RL, et al, "On-line power estimation of large diesel engine using acoustic emission and instantaneous crankshaft angular velocity," Proc IMechE Int J Eng Res, p. 399-410, 2006.

[69] R. Johnsson, "Crankshaft Speed Measurements And Analysis For Control And Diagnostics Of Diesel," Deparrmenr of Human Work Sciences, no. 1402 - 1757, 2001.

[70] Li Y, Gu F, Harris G, et al, "The measurement of instantaneous angular speed," Mech Sys Signal Proc , vol. 19, no. 786-805, 2005.

[71] Gu F, Yesilyurt I, Li Y, et al, "An investigation of the effects of measurement noise in the use of instantaneous angular speed for machine diagnosis," Mech Sys Signal Proc, vol. 20, no. 1444-1460, 2006.

[72] Cedric Peetersa, Quentin Leclereb, Jer ome Antonib et al., "Review and comparison of tacholess instantaneous speed estimation methods on experimental vibration data," Journal of Mechanical Systems and Signal Processing, 2019.

[73] N. H. Pontoppidan, "Condition Monitoring and Management from Acoustic Emissions," no. 0909-3192, 2005.

[74] Z. Jiang, Z. Mao , Z. Wang and J. Zhang , "Fault Diagnosis of Internal Combustion Engine," Sensors mdpi, no. 2916, p. 18, 2017.

[75] W Abdou, C Hunter, M F Shehadeh, JA Steel and R L Reuben, "Monitoring of Diesel Fuel Injection Using Acoustic," The Fifth International Conference on Condition Monitoring \& Machinery Failure Prevention Technologies, no. 308611610, 2016.

[76] D. P. LOWE, T. R. LIN, W. WU and A . C. TAN, "Diesel Knock Combustion And Its Detection Using," 211. 
[77] A. I. Alahmer, W. M. Adaileh and M. A. Al Zubi, "Monitoring of a spark ignition engine malfunctions," International Journal of Vehicle Noise and Vibration, vol. 10, no. 3, 2014.

[78] D. Ning, J. Hou, Y. Gong, Z. Zhang and C. Sun, "Auto-identification of engine fault acoustic signal through inverse trigonometric instantaneous frequency analysis," Advances in Mechanical Engineering, vol. 8, no. 1-8, 2016.

[79] R. M. Douglas, "Monitoring of The Piston Ring-Pack," PHD thesis,Department of Mechanical Engineering, School of Engineering, 2007.

[80] Brian Dykas and James Harris, "Acoustic Emission Sensing for Maritime Diesel Engine Performance and Health," ResearchGate, no. 016-487, 2016.

[81] S. Putwattana and P. Nivesrangsan, "The study of fuel injector operation using acoustic emission signals," International Conference on Business and Industrial Research (ICBIR), 2018.

[82] J. A. Steel,P. Nivesrangsan and R. L. Reuben, "Acoustic emission mapping of diesel engines for spatially located time series-Part II: Spatial reconstitution," Mechanical Systems and Signal Processing, vol. 21, no. 1084-102, 2007.

[83] Elamin and Fathi, "Fault detection and diagnosis in heavy duty diesel engines using acoustic emission," Ph.D., 2013.

[84] Elghamry and Mohamed Hussein, "Performance and condition monitoring of reciprocating machines using acoustic emission," ProQuest Dissertations Publishing, no. U124439, 2000.

[85] Nivesrangsan, P., J.A. Steel, and R.L. Reuben, " Acoustic emission mapping of diesel engines for spatially located time series-Part II," Mechanical Systems and Signal Processing, vol. 21, pp. 1084-1102, 2017.

[86] Lim, T., et al. , "Predicting AE attenuation in structures by geometric analysis," International Conference on Shape Modeling and Applications, 2005. 